\title{
“REFLEXÕES SOBRE ALFABETIZAÇÃO”
}

Ionice da Silva Debus1

O livro "Reflexões sobre Alfabetização" é uma significativa contribuição de Emília Ferreiro para os educadores da contemporaneidade. A obra nos traz importantes reflexões que nos fazem repensar a prática escolar da alfabetização, como resultados de suas pesquisas científicas. Assim, no primeiro tópico "A representação da linguagem e o Processo de Alfabetização", a autora nos mostra que o processo de aprendizagem da alfabetização inicial é caracterizado por somente os dois pólos, quem ensina e quem aprende, sem levar em conta o terceiro, a natureza do objeto de conhecimento envolvendo esta aprendizagem. Dentro deste tópico, apresenta três subitens, "A escrita como sistema de representação", "As concepções das crianças a respeito do sistema de escrita" e "As concepções sobre a língua subjacentes à prática docente", os quais serão exemplificados posteriormente. No segundo tópico, "Processos de aquisição da língua escrita no contexto escolar", nos traz que dificilmente reconhecemos que o desenvolvimento da leitura e da escrita começa muito antes da escolarização. No terceiro tópico "O espaço da leitura e da escrita na educação pré-escolar", ela discute os questionamentos feitos na educação pré-escolar de quando se deve começar a introduzir a leitura e a escrita, pois este acesso começa no dia e hora que os adultos decidem.

O subitem 1 "A escrita como sistema de representação" trabalha a diferença essencial entre codificação, onde as relações e os elementos já estão predeterminados e a criação de 
uma representação, onde nem os elementos, nem as relações estão predeterminados. Esta dicotomia de conceitos se torna dramática, pois se a escrita é concebida como um código de transcrição, sua aprendizagem é concebida como aquisição de uma técnica; mas se for concebida como um sistema de representação, sua aprendizagem se converte em um novo objeto de conhecimento, em uma aprendizagem conceitual.

No subitem 2, "As concepções das crianças a respeito do sistema de escrita", nos traz que as crianças são seres que ignoram que devem pedir permissão para começar a aprender, que portanto, possuem suas próprias concepções que devem ser levadas em consideração. O que predomina nas escolas é o modo tradicional de considerar a escrita infantil, onde se presta atenção apenas nos aspectos gráficos das produções, ignorando os construtivos. Diante disso, a autora nos mostra alguns exemplos de suas pesquisas, nas quais crianças foram reprovadas porque a professora não levou em consideração todo processo construtivo utilizado na sua escrita.

Fica, assim, ressaltada a importância de levar em consideração que as crianças são produtoras de conhecimento.

No subitem 3, "As concepções sobre a língua subjacentes à prática docente", questiona a prática alfabetizadora, centrada nos métodos, os quais não oferecem mais do que sugestões, incitações, práticas rituais ou conjuntos de proibições, não podendo criar conhecimento. As práticas baseadas nesses métodos levam a criança à convicção de que o conhecimento é algo que os outros possuem, sem nunca ser participante da construção do mesmo. Neste processo, o adulto já alfabetizado tem tendência a reduzir o conhecimento do leitor ao convencional.

Neste sentido, a partir dos anos oitenta observa-se um desinvestimento no estudo dos métodos de alfabetização, visto que surgiram pesquisas e discussões sobre a Teoria Construtivista 
de Jean Piaget, as Teorias Sócio-interacionistas de Lev Vygotsky e Henri Wallon, e os estudos de Emília Ferreiro e Ana Teberosky sobre a Psicogênese da Língua Escrita. Estas autoras, em especial, deram importante contribuição para as discussões no Brasil, pois trazem que o construtivismo não é um método de ensino, voltado para como o/a professor/a deve ensinar, pelo contrário, é uma teoria psicológica da aprendizagem que tem como objeto a psicogênese da inteligência e dos conhecimentos, portanto, voltada para como o sujeito aprende (FERREIRO; TEBEROSKY, 1985).

Estes novos conceitos trazidos pelas autoras causaram um grande impacto sobre a concepção que se tinha no Brasil sobre o processo de alfabetização, influenciando, inclusive, as normas dos Parâmetros Curriculares Nacionais.

Assim, as autoras fazem uma crítica importante à alfabetização tradicional, que dá um peso excessivo para o aspecto exterior da escrita, saber escrever, ou seja, o produto e deixa de lado a compreensão da natureza da escrita e sua organização. Por esse viés as crianças têm um processo ativo na aprendizagem, implicando uma transferência do foco da escola no conteúdo ensinado, para o sujeito que aprende, ou seja, o aluno.

A partir da obra de Emília Ferreiro na alfabetização, o uso das cartilhas começou a ser recusado, pois como defende, as cartilhas oferecem um universo artificial e desinteressante. Segundo ela, a escrita tem uma importante função social, e deve ser estimulada com o uso de textos atuais, jornais, livros, revistas, histórias. Com isso, a sala de aula se transforma em ambiente alfabetizador.

Neste sentido, a alfabetização é uma forma de se apropriar da função social da escrita, pois crianças de classes sociais diferentes apresentam desempenhos desiguais, em que nem todos têm o mesmo acesso a textos lidos e escritos desde os primeiros anos de vida. 
Com todas estas problematizações, a autora conclui que são necessárias mudanças nas bases para a alfabetização inicial, mas não no sentido de novos métodos ou materiais didáticos, mas de uma revolução conceitual a respeito da alfabetização.

No tópico "Processos de aquisição da língua escrita no contexto escolar", problematiza a questão dos educadores terem dificuldades em aceitar que as crianças comessem a aprendizagem da leitura e escrita antes da escolarização, onde deixam transparecer a ideia de que querem controlar o processo de aprendizagem e que a escola é a instituição criada para realizar este processo.

Com a utilização de métodos tradicionais, a alfabetização introduz aos alunos à leitura de palavras simples e sonoras, como papa, babá, bebê, mas que, quanto à assimilação da criança, não se ligam a nada, porém, a relação que a criança estabelece com o texto inteiro é enriquecedora desde o início do processo.

Porém, felizmente as crianças não esperam ter uma professora a sua frente para começar a aprender, desde que nascem são construtoras de conhecimento, no esforço de compreender o mundo que as rodeia, levantam problemas difíceis e abstratos e por si próprias descobrem respostas para eles.

A aprendizagem da lecto-escrita é muito mais que aprender a conduzir-se de modo apropriado com este tipo de objeto cultural, é a construção de um novo objeto de conhecimento, que não pode ser diretamente observado de fora.

Com isso, as crianças testam diversas hipóteses estranhas a nosso modo de pensar, para compreender a natureza do sistema de escrita que a sociedade lhes oferece e para isso, são obrigadas a reconstruí-lo internamente, em vez de recebê-lo como um conhecimento pré-elaborado.

No tópico "O espaço da leitura e da escrita na educação pré-escolar", nos traz a crítica a respeito do questionamento de ensinar ou não a ler e escrever na pré-escola. Esta dúvida 
está mal colocada, segundo a autora, porque tanto a resposta negativa quanto a positiva apóia-se em um pressuposto que não é discutido, que o acesso à língua escrita começa no dia e hora que os adultos decidem.

Esta reflexão é muito positiva, pois nos mostra que quando se decide que não devemos ensinar a ler e escrever na pré-escola, as salas sofrem um processo de limpeza, onde são retirados quaisquer traços da língua escrita. Até mesmo a professora tem um cuidado com a leitura na frente das crianças, onde conta histórias, mas nunca as lê em voz alta. Já quando se decide ensinar, a sala e a prática docente passam a se assemelhar a do primeiro ano, seguindo modelos tradicionais de exercícios de motricidade, com cópias intermináveis e nenhum uso funcional da língua escrita.

Estes exemplos nos dão a dimensão do trabalho na sala de aula, em que alguns professores pensam o ensino como momentos separados, não há uma continuidade, e sim, uma ruptura no processo. Geralmente, no primeiro ano, desconsidera-se tudo que estava sendo desenvolvido e se passa a priorizar a leitura e a escrita de maneira mecânica, deixando de lado outras aprendizagens necessárias nesta fase do desenvolvimento.

Ainda, quando estão escrevendo, é somente aquela palavra, descontextualizada de tudo que a criança já conhece. Algo pronto, que geralmente o professor impõe por entender que é importante e que está na hora do aluno aprender. Como também, é da mesma maneira para todos, desconsiderando que cada um tem seu tempo de assimilação e cada aluno aprende de um jeito diferente.

Outra discussão trazida é em relação à diferença no processo de aprendizagem das crianças do meio rural e do meio urbano. Os professores precisam entender que o meio tem muita influência em como as crianças aprendem e também em que nível elas estão no processo, que conhecimentos prévios trazem para a escola. 
As crianças do meio urbano iniciam seu processo de aprendizagem muito antes da escola, porque a escrita faz parte da paisagem urbana e a vida requer continuamente o uso da leitura, onde as crianças desde muito cedo tentam compreender informações das mais variadas procedências, recebendo informação sobre a função social da escrita participando desses atos.

Porém, as crianças do meio rural ficam em desvantagem em relação às urbanas, onde a escrita não é tão presente na paisagem, ficando este papel à escola, de proporcionar às crianças a liberdade de experimentar os sinais escritos e a leitura. A autora encerra esta discussão afirmando que é papel das escolas darem às crianças ocasiões de aprender, onde a língua escrita deve ser entendida muito mais que um conjunto de formas gráficas, mas um objeto social parte de nosso patrimônio cultural.

Cabe salientar que a autora defende os esquemas conceituais que as crianças elaboram não como simples reproduções das informações recebidas do meio, ao contrário, são processos construtivos em que a criança leva em consideração parte da informação recebida e introduz sempre algo subjetivo. Neste sentido, o meio serve de estímulo, mas o resultado é sempre algo a mais, uma construção da própria criança.

Nesta mesma perspectiva está o papel do professor, que tem suas intervenções também como mediadoras do processo de aprendizagem na alfabetização, em que a passagem de um nível para outro é gradual e depende de como vai ser trabalhada cada etapa.

Assim, como nos traz a obra de Emília Ferreiro, alfabetizar é construir conhecimento, em que, para ensinar a ler e escrever faz-se necessário compreender que os alfabetizandos terão que lidar com dois processos paralelos: as características do sistema de escrita e o uso funcional da linguagem.

Após a leitura da obra, pode-se destacar a importância da 
mesma para os educadores, pois a autora traz importantes contribuições para as discussões da alfabetização e seus desafios, tema este, muito presente no cotidiano escolar e no meio docente. Sendo assim, se constitui em leitura obrigatória a todos aqueles que almejam exercer a docência com coerência.

\section{Referências}

FERREIRO, Emilia; TEBEROSKY, Ana. Psicogênese da Língua Escrita. Porto Alegre: Artes Médicas, 1985. 284 p.

FERREIRO, Emília. Reflexões sobre alfabetização. 24 ed., Cortez: São Paulo, 2001.

Notas

${ }^{1}$ Pedagoga. Mestranda em Educação pelo Programa de Pós-Graduação em Educação da Universidade Federal de Santa Maria. 